\title{
PENGARUH PROGRAM EMPATHIC CARING CONSULTATION TERHADAP PROFESSIONAL QUALITY OF LIFE PADA PSIKOLOG
}

\author{
Anya Asbar, Maya Khairani ${ }^{1}$, Marty Mawarpury \\ Program Studi Psikologi Fakultas Kedokteran Universitas Syiah Kuala
}

\begin{tabular}{l}
\hline Keywords/Kata kunci \\
\hline empathic caring \\
consultation, \\
compassion satisfaction, \\
professional quality of \\
life, secondary trauma \\
stress.
\end{tabular}

empathic caring consultation, compassion satisfaction, professional quality of life, secondary trauma stress.

\begin{abstract}
ABSTRAK:
This study aims to determine the effect of the Empathic Caring Consultation (ECC) program on Professional Quality of Life (ProQOL) in psychologists. This study involved seven psychologists. The research sample was taken using purposive sampling method. The research method used was one group pretest-post test design. ProQOL is measured using the Professional Quality of Life Version V scale, while the implementation of ECC training refers to the concept of Prawitasari. Analysis using Wilcoxon signed-rank test with a significant value $(p)=0.340$ (BO); 0.932 (STS); 0.496 (CS) ( $p>0.05)$. The results of the study showed that there was no effect of the ECC program on ProQOL on psychologists. This is because there are several variations of the three ProQOL components before and after treatment.
\end{abstract}

Penelitian ini bertujuan untuk mengetahui pengaruh program Empathic Caring Consultation (ECC) terhadap Professional Quality of Life (ProQOL) pada psikolog. Penelitian ini melibatkan tujuh psikolog. Pengambilan sampel penelitian menggunakan metode purposive sampling. Metode penelitian yang digunakan adalah desain one group prates-paskates. ProQOL diukur menggunakan skala Professional Quality of Life Version V, sedangkan pelaksanaan pelatihan ECC merujuk pada konsep Prawitasari. Analisis menggunakan wilcoxon signed-rank test dengan nilai signifikan (p)=0.340 (BO); 0.932(STS); 0.496(CS) (p>0.05). Hasil penelitian menunjukkan tidak terdapat pengaruh program ECC terhadap ProQOL pada psikolog. Hal ini terdapat beberapa variasi dari tiga komponen ProQOL sebelum dan sesudah pemberian perlakuan.

\footnotetext{
${ }^{1}$ Korespondensi mengenai artikel ini dapat dilakukan melalui: khairani.maya@unsyiah.ac.id
} 
Lingkungan kerja yang berfokus pada pemberian dukungan dan bantuan kepada klien cenderung berpotensi menimbulkan stres (Wagaman et al., 2015). Hal ini dikarenakan paparan penderitaan klien terhadap profesi yang membantu korban seperti penolong (helper) dapat menjadi ancaman bagi kualitas hidup profesional (Figley, 2012). Kualitas hidup profesional (professional quality of life) adalah kualitas yang dirasakan individu sehubungan dengan pekerjaannya sebagai penolong (Stamm, 2010).

Penolong akan rentan terhadap dua hal yaitu secondary trauma stress dan burnout (Lloyd et al., 2002) yang merupakan efek negatif dari professional quality of life (Stamm, 2010). Stamm (2010) mengemukakan bahwa saat penolong mengalami secondary trauma stress dan burnout, secara bersamaan pula mengalami compassion satisfaction yang merupakan efek positif dari professional quality of life. Menurut Stamm (2010), program pencegahan organisasional dapat membantu memaksimalkan kesejahteraannya sebagai penolong yang disebut dengan compassion satisfaction, dan dapat mengurangi risiko burnout dan secondary trauma stress.

Dalam dunia kerja, penolong dapat ditemukan pada profesi perawat kesehatan (Stamm, 2010), khususnya pada psikolog. Psikolog memiliki kewenangan untuk memberikan layanan psikologi (Putri \& Masykur, 2017) berupa menolong individu atau kelompok untuk penyelesaian masalahmasalah psikologis dengan memberikan praktik konseling dan psikoterapi, layanan masyarakat, intervensi sosial dan klinis (Himpunan Psikologi Indonesia, 2010). Menurut Wagaman et al., (2015) hubungan antara secondary trauma stress dan burnout menunjukkan bahwa saat berbagi perasaan pada klien dapat merugikan kesehatan mental individu, walaupun begitu individu didorong untuk bersikap empati. Jenkins \&
Warren (2012) mengidentifikasi konsekuensi yang dihasilkan dari secondary trauma stress dan burnout yaitu kehilangan empati.

Penelitian yang dilakukan Duarte et al., (2016) menunjukkan bahwa empati dapat memprediksikan tiga aspek professional quality of life. Kemampuan berempati terhadap orang lain adalah salah satu keterampilan penting dalam praktik kerja (Gerdes \& Segal, 2011), hal ini diperlukan bagi penolong untuk mempelajari keterampilan kompetensinya saat terlibat dengan klien (Wagaman et al., 2015). Empati mengacu kepada kapasitas untuk memahami dan menanggapi pengalaman afektif unik orang lain dengan tingkat deskripsi pengalaman, sarana psikologis berupa empati dapat menunjukkan rasa kesamaan antara perasaan sendiri dan yang diungkapkan orang lain (Decety \& Jackson, 2006).

Menurut Gerdes \& Segal (2009) dalam meningkatkan empati seseorang, maka dapat dipraktikkan dan dikembangkan secara terus-menerus agar dapat berkembang dengan baik sesuai dengan potensi yang dimilikinya, indikator dari empati itu sendiri yaitu mampu menerima sudut pandang orang lain, memiliki kepekaan terhadap perasaan orang lain, dan mampu mendengarkan orang lain. Salah satu cara yang dapat meningkatkan compassion satisfaction, mencegah burnout dan secondary trauma stress pada penolong adalah dengan memberikan intervensi pelatihan empati.

Pelatihan empati yang diberikan pada penelitian ini adalah Program "Empathic Caring Consultation" (ECC) untuk Psikolog. Program tersebut dikembangkan Prawitasari, Hadiyono, Tana, dan Sunartono pada tahun 2004 (dalam Prawitasari et al., 2010). ECC merupakan konsultasi penuh perhatian dengan mempelajari cara berempati ketika bertemu dengan orang lain 
yang mengalami kesulitan dalam hal mendengarkan aktif dan ekspresi komunikasi verbal dan nonverbal. Program ECC telah diaplikasikan pada profesi dokter (Prawitasari et al., 2010), dokter gigi dan perawat gigi (Khairani \& Prawitasari, 2009), dan bidan (Ardhiani, 2012).

Berdasarkan uraian di atas, maka rumusan hipotesis yang diajukan dalam penulisan ini adalah "terdapat pengaruh program Empathic Caring Consultation terhadap Professional Qualiy of Life pada psikolog".

\section{METODE PENELITIAN}

Penelitian ini merupakan jenis penelitian kuantitatif-eksperimen yang menggunakan metode model PreExperimental Design dengan bentuk OneGroup Prates-Paskates Design. Subjek pada penelitian ini berjumlah tujuh psikolog dengan kriteria yaitu melakukan pelayanan psikologi dan bersedia mengikuti pelatihan ECC selama satu hari penuh.

Penelitian ini menggunakan skala Professional Quality of Life Scale Version $V$ (ProQOL-V Scale) yang dikembangkan Stamm (2010). Skala professional quality of life Version V (ProQOL-V) terdiri dari 30 aitem berdasarkan tiga komponen professional quality of life (ProQOL), yaitu: Compassion Satisfaction, Burnout, dan Secondary Trauma Stress. Skala ProQOL-V menggunakan skala Likert dengan lima alternatif pilihan jawaban yaitu, 1 tidak pernah, 2 jarang, 3 kadang-kadang, 4 sering, dan 5 sangat sering, dengan jumlah kategori minimal 10 dan kategori maksimal $50 \mathrm{di}$ setiap sub skalanya, namun, pada aitem 1,4 , 15, 17, dan 29 harus dibalik ketika skoring. Interpretasi dilakukan melalui hasil skoring terhadap skala yang diisi oleh sampel. Kemudian hasil kategori diinterpretasikan ke dalam 3 kategori professional quality of life di setiap komponennya.
Penelitian ini juga menggunakan modul Empathic Caring Consultation (ECC) yang dikembangkan Prawitasari tahun 2004. Modul Program ECC merupakan panduan pelaksanaan intervensi yang ditunjukkan kepada psikolog. Prinsip pembelajaran pelatihan ini yaitu experiential training, didactic and experiential, skill training, didactic and skill training, mindfulness training, video stimulus training, dan writing training. ECC meliputi enam tahapan yaitu: a) pembukaan, b) materi empathic caring consultation, c) melakukan relaksasi, d) mengamati dua video mengenai empati dan konsultasi antara klien dengan psikolog, e) memberikan kesempatan kepada subjek untuk latihan menggunakan keterampilan berempati dengan bermain peran, dan f) materi professional quality of life.

Hal yang dipersiapkan pertama adalah perijinan menggunakan modul ECC, kemudian pemilihan subjek untuk dapat mengikuti pelatihan, selanjutnya pemilihan fasilitator untuk memandu proses intervensi, adapun fasilitator yang terlibat pada pelatihan ECC yaitu tiga psikolog klinis. Langkah selanjutnya adalah persiapan modul. Sebelum intervensi dilakukan, dilakukannya proses pengambilan data pertama dengan memberikan skala ProQOLV kepada subjek. Selanjutnya, diberikan intervensi ECC selama satu hari penuh. Lebih kurang satu bulan setelah pelatihan ECC, diberikan kembali skala ProQOL-V kepada subjek.

Teknik analisis data yang digunakan dalam penelitian ini, non-parametrik, yaitu Wilcoxon Paired-Rank. Analisis tersebut digunakan karena jumlah sampel yang sedikit dan keadaan subjek penelitian yang diukur berada pada dua situasi dan dengan kriteria yang spesifik. 


\section{HASIL PENELITIAN}

Penelitian ini bertujuan untuk mengetahui pengaruh ECC terhadap professional quality of life pada psikolog. Sampel yang digunakan dalam penelitian adalah tujuh psikolog yang merupakan anggota Ikatan Psikolog Klinis (IPK) Wilayah Aceh dan memberikan layanan psikologi klinis di Rumah Sakit Daerah maupun Rumah Sakit Jiwa.
Pembagian kategori sampel yang digunakan peneliti adalah kategori Professional Quality of Life oleh Stamm (2010). Pengkategorian terdiri dari tiga kategori yaitu rendah, sedang, dan tinggi. Berdasarkan hal tersebut, peneliti melakukan kategorisasi skor tiap-tiap subjek penelitian pada masing-masing komponen professional quality of life. Hasil kategorisasi tersebut dapat dilihat pada tabel 1 berikut ini:

Tabel 1. Kategori Professional Quality of Life Sebelum Perlakuan

\begin{tabular}{|c|c|c|c|c|}
\hline Komponen & Kategori & Kriteria & $\mathbf{F}$ & Persentase \\
\hline \multirow[t]{3}{*}{ Burnout } & Rendah & $10-22$ & 3 & $43 \%$ \\
\hline & Sedang & $23-41$ & 4 & $57 \%$ \\
\hline & Tinggi & $42-50$ & 0 & 0 \\
\hline \multirow[t]{3}{*}{ Secondary Trauma Stress } & Rendah & $10-22$ & 7 & $100 \%$ \\
\hline & Sedang & $23-41$ & 0 & 0 \\
\hline & Tinggi & $42-50$ & 0 & 0 \\
\hline \multirow[t]{3}{*}{ Compassion Satisfaction } & Rendah & $10-22$ & 0 & 0 \\
\hline & Sedang & $23-41$ & 4 & $57 \%$ \\
\hline & Tinggi & $42-50$ & 3 & $43 \%$ \\
\hline
\end{tabular}

Dari tabel 1 diperoleh hasil kategorisasi professional quality of life sebelum perlakuan yang menunjukkan komponen burnout pada psikolog berada di kategori sedang yaitu sebanyak 57\% (4 psikolog), sedangkan sisanya berada pada kategori rendah sebanyak 43\% (3 psikolog). Pada komponen secondary trauma stress menunjukkan mayoritas subjek berada pada kategori rendah yaitu 100\% (7 psikolog). Sedangkan pada komponen compassion satisfaction menunjukkan subjek berada pada kategori sedang sebanyak 57\% (4 psikolog) dan sisanya berada pada kategori tinggi 43\% (3 psikolog). Selanjutnya, pada kategorisasi professional quality of life sesudah perlakuan dijabarkan pada tabel 2 sebagai berikut:

Tabel 2. Kategori Professional Quality of Life Sesudah Perlakuan

\begin{tabular}{llccc}
\hline Komponen & Kategori & Kriteria & F & Persentase \\
\hline Burnout & Rendah & $10-22$ & 5 & $71 \%$ \\
& Sedang & $23-41$ & 2 & $29 \%$ \\
& Tinggi & $42-50$ & 0 & 0 \\
\hline Secondary Trauma Stress & Rendah & $10-22$ & 6 & $86 \%$ \\
& Sedang & $23-41$ & 1 & $14 \%$ \\
& Tinggi & $42-50$ & 0 & 0 \\
\hline Compassion Satisfaction & Rendah & $10-22$ & 0 & 0 \\
& Sedang & $23-41$ & 5 & $71 \%$ \\
& Tinggi & $42-50$ & 2 & $29 \%$ \\
\hline
\end{tabular}


Dari tabel 2 diperoleh hasil kategorisasi professional quality of life sesudah perlakuan pada komponen burnout menunjukkan mayoritas subjek berada pada kategori rendah sebanyak 71\% (5 psikolog), sedangkan sisanya berada pada kategori sedang sebanyak 29\% (2 psikolog). Pada komponen secondary trauma stress, mayoritas subjek berada pada kategori rendah sebanyak $86 \% \quad$ (6 psikolog), sedangkan sisanya berada pada kategori sedang sebanyak $14 \% \quad(1 \quad$ psikolog). Kemudian pada komponen compassion satisfaction, mayoritas subjek berada pada kategori sedang 71\% (5 psikolog) dan sisanya berada pada kategori tinggi 29\% (2 psikolog). Selanjutnya dilakukan pengujian professional quality of life pada psikolog dengan menggunakan uji Wilcoxon dengan SPSS. Tabel 3 berikut ini akan menjelaskan hasil pengujian tersebut:

Tabel 3. Analisis Uji Wilcoxon Professional Quality of Life

\begin{tabular}{|c|c|c|c|c|c|c|}
\hline Professional Quality of Life & & $\mathbf{N}$ & Mean Rank & Sum of Ranks & $\mathbf{Z}$ & Sig. \\
\hline $\mathrm{BO}$ & $\mathrm{N}$ & 5 & 3,00 & 15,00 & $-0,964$ & 0,340 \\
\hline \multirow[t]{2}{*}{ Sebelum dan Sesudah } & $\mathrm{P}$ & 1 & 6,00 & 6,00 & & \\
\hline & $\mathrm{T}$ & 1 & & & & \\
\hline STS & $\mathrm{N}$ & 4 & 3,63 & 14,50 & $-0,085$ & 0,932 \\
\hline \multirow[t]{2}{*}{ Sebelum dan Sesudah } & $\mathrm{P}$ & 3 & 4,50 & 13,50 & & \\
\hline & $\mathrm{T}$ & 0 & & & & \\
\hline $\mathrm{CS}$ & $\mathrm{N}$ & 3 & 3,33 & 10,00 & $-0,680$ & 0,496 \\
\hline \multirow[t]{2}{*}{ Sebelum dan Sesudah } & $\mathrm{P}$ & 2 & 2,50 & 5,00 & & \\
\hline & $\mathrm{T}$ & 2 & & & & \\
\hline
\end{tabular}

\section{Keterangan:}

NR : Negative Rank atau selisih negatif

PR : Positif Rank atau selisih positif

$\mathrm{T} \quad$ : Ties (kesamaan nilai sebelum dan sesudah)

Berdasarkan tabel 3, interpretasi output uji wilcoxon menunjukkan negative ranks (selisih negatif) komponen burnout terdapat 5 subjek yang mengalami penurunan dengan rata-rata 3,00 dan sum of ranks sebesar 15,00, serta 1 subjek yang mengalami peningkatan burnout dengan rata-rata 6,00 dan sum of ranks sebesar 6,00. Pada komponen burnout terdapat 1 subjek yang memiliki kesamaan nilai prates dan paskates.

Pada komponen secondary trauma stress menunjukkan 4 subjek yang mengalami penurunan dengan rata-rata 3,63 dan sum of ranks 14,50 dan 3 subjek yang mengalami peningkatan dengan ratarata 4,50 dan sum of ranks 13,50 . Selanjutnya pada komponen compassion satisfaction menunjukkan bahwa terdapat 3 subjek yang mengalami penurunan dengan rata-rata 3,33 dan sum of ranks 10,00 dan terdapat 2 subjek yang mengalami peningkatan dengan rata-rata 2,50 dan sum of ranks 5,00, serta menunjukkan terdapat 2 subjek yang memiliki kesamaan nilai prates dan paskates pada komponen compassion satisfaction.

Berdasarkan tabel 3, hasil menunjukkan bahwa nilai signifikansi 0,340 (BO); 0,932 (STS); 0,496 (CS) > dari 0,05 yang menunjukkan bahwa hipotesis penelitian ditolak sehingga dapat disimpulkan tidak terdapat pengaruh program empathic caring consultation terhadap professional quality of life pada psikolog. 


\section{PEMBAHASAN}

Hasil penelitian ini menunjukkan bahwa tidak terdapat pengaruh empathic caring consultation (ECC) terhadap professional quality of life pada psikolog. Berdasarkan hasil penelitian, peneliti menganalisis skor Professional Quality of Life subjek sebelum dan sesudah diberikan Empathic Caring Consultation, dan menghasilkan bahwa perubahan kategori subjek hanya menunjukkan 28 persen penurunan burnout dan 14 persen mengalami peningkatan secondary trauma stress yang kemudian hanya 14 persen yang mengalami peningkatan compassion satisfaction. Hasil penelitian yang dilakukan Prawitasari et al., (2010) juga menunjukkan tidak terdapat pengaruh Empathic Caring Consultation (ECC) pada penggunaan analgesika di empat puskesmas yang diteliti, dikarenakan persepsi pasien terhadap kualitas pelayanan di kelompok eksperimen meningkat sedikit.

Professional quality of life terdiri dari tiga komponen, diantaranya adalah burnout. Stamm (2010) mengatakan bahwa burnout adalah perasaan putus asa dan kesulitan dalam berurusan dengan pekerjaan atau dalam melakukan pekerjaan, hal ini terkait dengan beban kerja yang sangat tinggi atau lingkungan kerja yang tidak mendukung. Hasil penelitian menunjukkan bahwa terdapat dua subjek yang mengalami burnout pada kategori sedang sebelum dan sesudah diberikan perlakuan dan 5 subjek berada pada kategori rendah sebelum dan sesudah diberi perlakuan. Dua subjek tersebut diperkirakan mengalami burnout, karena kinerja sebagai penolong dapat terganggu seperti halnya burnout yang meningkat dan berkurangnya kapasitas untuk empati (Whitfield \& Kanter, 2014).

Dari hasil penelitian ini menunjukkan bahwa sindrom burnout khusus untuk konteks kerja dan merupakan hasil suatu kegiatan antara pekerja dan konteks profesionalnya, hal ini termasuk budaya, norma, dan nilai-nilai yang terkait dengan profesi, yang secara langsung berdampak pada bagaimana pekerja memandang dan menilai lingkungan kerja mereka dan mengalami burnout (Berjot et al., 2017). Stamm (1997) juga mengungkapkan bahwa burnout tidak terkait pada reaksi terhadap permasalahan klien yang mengalami trauma, namun burnout terkait dengan karakteristik tempat kerja, seperti halnya ukuran beban kasus dan tekanan kelembagaan.

Komponen kedua yang akan dibahas ialah secondary trauma stress. Stamm (2010) menjelaskan bahwa secondary trauma stress berkaitan dengan pekerjaan, paparan sekunder terhadap orang-orang yang mengalami peristiwa yang sangat traumatis dan penuh stres. Hasil penelitian menunjukkan bahwa terdapat satu subjek yang mengalami peningkatan kategori rendah menjadi kategori sedang, jika dilihat data demografi, subjek merupakan psikolog yang bekerja di rumah sakit dengan lama bekerja lebih kurang 13 tahun. SodekeGregson et al., (2013) mengungkapkan bahwa orang yang bekerja sebagai penolong berada pada risiko mengalami peningkatan secondary trauma stress. Hal ini dikarenakan ketika psikolog mendengarkan pengalaman klien mengenai trauma, kegelisahan, rasa sakit, depresi, atau semacam tekanan lain, dengan maksud untuk memahami dan membantu penderitaan klien, psikolog akan cenderung sedikit banyaknya merasakan emosi itu sendiri (Dehlin \& Lundh, 2018). Sedangkan enam subjek tetap berada pada kategori rendah, menurut Nelson-Gardell \& Harris (2003) hal ini dikarenakan seiring bertambahnya usia, resiko untuk secondary trauma stress menjadi menurun.

Sodeke-Gregson et al., (2013) mengungkapkan bahwa secondary trauma stress dapat berkembang melalui paparan traumatis klien yang berkepanjangan. Hal ini dikarenakan subjek selama kurang lebih 13 
tahun bekerja sebagai Psikolog dan mengalami paparan traumatis klien yang ditangani selama 13 tahun tersebut. Bagi subjek yang berada pada kategori rendah sebelum dan sesudah diberikan perlakuan, hal ini dapat disebabkan karena biasanya penolong profesional menyadari pentingnya waktu luang, perawatan diri, dan keseimbangan kehidupan kerja yang sehat (Whitfield \& Kanter, 2014).

Komponen terakhir dari professional quality of life adalah compassion satisfaction. Hansen et al., (2018) mendefiniskan compassion satisfaction sebagai konsekuensi kognitif dan emosional yang positif sebagai hasil dari perasaan empati, konsekuensi ini termasuk perasaan yang diperkuat dengan puas dengan situasi sendiri, berkembang secara pribadi, dan sejenisnya. Hasil penelitian menunjukkan komponen compassion satisfaction terdapat subjek yang mengalami penurunan kategori yang awalnya berada pada kategori tinggi kemudian menjadi kategori sedang.

Tidak hanya itu, hasil penelitian juga menunjukkan enam subjek tetap berada pada kategori sedang maupun tinggi sebelum dan sesudah diberikan perlakuan. Hal ini dikarenakan penolong yang bekerja dengan klien yang menderita sakit dapat mengalami compassion satisfaction yang merupakan kesenangan yang diperoleh dari membantu orang lain (Stamm, 2010) dan ditemukan bahwa compassion satisfaction berkorelasi positif dengan resiliensi, yaitu kemampuan untuk mengatasi, belajar, dan tumbuh dari pengalaman yang sulit (Burnett, 2015). Selain itu menurut Burnett (2015) dalam meningkatkan compassion satisfaction disarankan pekerja perlu mengandalkan strategi perawatan diri (selfcare) sebagai perlindungan dari efek serius keterlibatan empati.

Penelitian ini masih memiliki beberapa keterbatasan, diantaranya penelitian ini menunjukkan hasil bahwa tidak ada pengaruh program empathic caring consultation (ECC) terhadap professional quality of life (ProQOL), sehingga program empathic caring consultation diharapkan dapat kembali diperhatikan proses penelitiannya dan memodifikasi program ECC sesuai dengan kebutuhan psikolog. Selain itu, penelitian ini tidak melakukan kontrol terkait skor variabel yang ingin diberikan perlakuan (tidak adanya screening di awal perlakuan) dan juga terdapat 34 psikolog yang aktif terdaftar di Sistem Informasi Keanggotaan Himpunan Indonesia, sehingga hal tersebut memberikan keterbatasan peneliti dikarenakan sampel yang ada pada penelitian ini merupakan sampel yang sukarela mengikuti Empathic Caring Consultation dan juga pengalaman subjek yang sering mengikuti pelatihan dengan profesinya sebagai psikolog. Oleh sebab itu, penelitian ini masih banyak kekurangan.

\section{SIMPULAN DAN SARAN}

Dari hasil penelitian ini dapat disimpulkan bahwa tidak terdapat pengaruh Program Empathic Caring Consultation terhadap Professional Quality of Life pada Psikolog ( $\mathrm{p}>0,05)$. Hasil penelitian menunjukkan terdapat beberapa variasi dari tiga komponen Professional Quality of Life sebelum dan sesudah pemberian perlakuan.

Hasil penelitian secara rinci, komponen burnout menunjukkan bahwa sebelum diberikan perlakuan terdapat tiga subjek yang berada pada skor rendah dan empat subjek yang berada pada skor sedang, setelah diberikan perlakuan hanya terdapat dua subjek yang mengalami skor rendah dari awalnya berada pada skor sedang, dan satu subjek yang tetap berada pada skor sedang. Kemudian pada komponen secondary trauma stress menunjukkan bahwa sebelum diberikan perlakuan, seluruh subjek pada skor rendah, setelah diberikan perlakuan hanya satu subjek yang mengalami skor sedang. Selanjutya pada komponen 
compassion satisfaction menunjukkan bahwa sebelum diberikan perlakuan subjek berada pada skor sedang dan tinggi, setelah diberikan perlakuan terdapat satu subjek yang mengalami skor sedang yang pada awalnya skor tinggi.

\section{Saran}

Berdasarkan hasil penelitian yang telah dilakukan, ada beberapa saran yang ingin peneliti ajukan agar menjadi pertimbangan, yaitu psikolog diharapkan tetap belajar baik melalui kegiatan pelatihan maupun kegiatan penunjang lain yang dapat membantu meningkatkan Professional Quality of Life. Peneliti menyadari bahwa penelitian ini jauh dari sempurna dan masih banyak memiliki kekurangan. Adapun saran bagi peneliti selanjutnya yang ingin melakukan penelitian serupa, diharapkan peneliti memodifikasi ECC sesuai dengan kebutuhan psikolog agar program ini dapat membantu meningkatkan professional quality of life.

\section{DAFTAR PUSTAKA}

Ardhiani, L. N. (2012). Mengenal potensi bidan. In Psikologi Terapan. Penerbit Erlangga.

Berjot, S., Altintas, E., Grebot, E., \& Lesage, F. X. (2017). Burnout risk profiles among french psychologists. Burnout Research, 7, 10-20. https://doi.org/https://doi.org/10.10 16/j.burn.2017.10.001

Burnett, H. J. (2015). The compassion fatigue and resilience connection: A survey of resilience, compassion fatigue, burnout, and compassion satisfaction among trauma responders. International Journal of Emergency Mental Health and Human Resilience, 17(1), 318-326.

https://doi.org/10.4172/15224821.1000165

Decety, J., \& Jackson, P. L. (2006). A socialneuroscience perspective on empathy. Current Directions in Psychological Science, 15(2), 54-58. https://doi.org/10.1111/j.09637214.2006.00406.x

Dehlin, M., \& Lundh, L. G. (2018). Compassion fatigue and compassion satisfaction among psychologists: Can supervision and a reflective stance be of help? Journal for Person-Oriented Research, 4(2), 95-107. https://doi.org/10.17505/jpor.2018.0 9

Duarte, J., Pinto-Gouveia, J., \& Cruz, B. (2016). Relationships between nurses' empathy, self-compassion and dimensions of professional quality of life: A cross-sectional study. International Journal of Nursing Studies, 60, 1-11. https://doi.org/10.1016/j.ijnurstu.20 16.02.015

Figley, C. R. (2012). Basics of compassion fatigue. Figley Institute.

Gerdes, K. E., \& Segal, E. A. (2011). Importance of empathy for social work practice: Integrating new science. Social Work, 56(2), 141-148.

Gerdes, K., \& Segal, E. (2009). A social work model of empathy. Advances in Social Work, 10(2), 114-127. https://doi.org/10.12691/education3-9-7

Hansen, E. M., Eklund, J. H., Hallén, A., Bjurhager, C. S., Norrström, E., Viman, A., \& Stocks, E. L. (2018). Does feeling empathy lead to compassion fatigue or 
compassion satisfaction? the role of time perspective. The Journal of Psychology, 152(8), 630-645. https://doi.org/10.1080/00223980.2 018.1495170

Himpunan Psikologi Indonesia, (HPI). (2010). Kode etik psikologi indonesia. Pengurus Pusat Himpunan Psikologi Indonesia.

Jenkins, B., \& Warren, N. A. (2012). Concept analysis: Compassion fatigue and effects upon critical care nurses. Critical Care Nursing Quarterly, 35(4), 388-395. https://doi.org/10.1097/CNQ.0b013e 318268fe09

Khairani, M., \& Prawitasari, J. . (2009). Peran program pelayanan empatik plus untuk dokter gigi-perawat gigi dalam meningkatkan kemampuan komunikasi dengan pasien gigi-mulut di puskesmas [Thesis, Universitas Gadjah Mada]. Universitas Gadjah Mada.

Lloyd, C., King, R., \& Chenoweth, L. (2002). Social work, stress and burnout: A review. Journal of Mental Health, 11(3), 255-265. https://doi.org/10.1080/0963823002 0023642

Nelson-Gardell, D., \& Harris, D. (2003). Childhood abuse history, secondary traumatic stress, and child welfare workers. Child Welfare, 82(1), 5-26. http://www.ncbi.nlm.nih.gov/pubmed $/ 12641376$

Prawitasari, J. E., Hadiwirawan, O., Winarti, H. D. H. S., \& Intriaty. (2010). Empathic caring consultation (ECC): Will it be able to improve the quality of care at the health centers? Anima Indonesian Psychological Journal, 26(1), 46-55.

Putri, I. G., \& Masykur, A. M. (2017). "Bertahan dalam dilema" (Studi fenomenologis menghadapi stres kerja pada psikolog klinis wanita). Empati; Vol 6, No 1 (2017): Januari 2017, 6(1), 239-245. https://ejournal3.undip.ac.id/index.ph p/empati/article/view/15081

Sodeke-Gregson, E. A., Holttum, S., \& Billings, J. (2013). Compassion satisfaction, burnout, and secondary traumatic stress in UK therapists who work with adult trauma clients. European Journal of Psychotraumatology, 4(1), 21869. https://doi.org/10.3402/ejpt.v4i0.218 69

Stamm, B. (1997). Work-related secondary traumatic stress. PTSD Research Quarterly, 8(2), 1-6.

Stamm, B. H. (2010). The concise PROQOL manual 2nd Ed. Pocatello PROQOL.org.

Wagaman, M. A., Geiger, J. M., Shockley, C., \& Segal, E. A. (2015). The role of empathy in burnout, compassion satisfaction, and secondary traumatic stress among social workers. Social Work, 60(3), 201-209. https://doi.org/10.1093/sw/swv014

Whitfield, N., \& Kanter, D. (2014). Helpers in distress: Preventing secondary trauma. Reclaiming Children and Youth, 22(4), 59-61. 
Anya Asbar, Maya Khairani \& Marty Mawarpury 